\title{
Haihtuvien rasvahappojen kvantitatiivinen määrittäminen pötsinesteestä ja säilörehusta kaasu-nestekromatograafisesti
}

\author{
LEA Huida \\ Maatalouden tutkimuskeskus, Kotieläinhoidon tutkimuslaitos, Tikkurila
}

Saapunut 24. 4. 1973

\section{Quantitative determination of volatile fatty acids from rumen sample and silage by gas-liquid chromatography}

LEA HuIdA,

Agricultural Research Centre, Department of Animal Husbandry, Tikkurila

\begin{abstract}
The gas-liquid chromatographic method used in this study for the determination of volatile fatty acids was reliable at concentrations of $10 \mathrm{ppm}$. The volatile fatty acids of silage and rumen samples were determinated by hydrogen flame ionization detector from water extract containing 5 per cent formic acid. The solid phase Chromosorb W (a.w. $60 / 80$ mesh) coated by diethylenglycolsuccinate (5 per cent) and ortophosphoric acid ( 1 per cent) was used as packing material of spiral glass column (length $2 \mathrm{~m}$, i.d. $3 \mathrm{~mm}$ ). The column filling had to be changed only after 2000 analyses. Acetic acid, propionic acid, butyric acid, isovaleric acid and valeric acid were determinated in 5 mins. The relative error percentages averaged respectively $1.17,1.67,2.55,3.21$ and 3.35. The relative error was greatest in the measurement of isovaleric and valeric acid, because their amount was one twentieth of the amount of acetic acid.

The prehandling of centrifuged rumen samples with saturated mercuric chloride and $1 \mathrm{~N} \mathrm{NaOH}$ and freeze drying seemed to be a good procedure before gas chromatographing, because the base line kept quite stable all the time. The pure volatile fatty acid solutions prehandled in the above-mentioned way remained unchanged in $-18^{\circ} \mathrm{C}$ for one year and so the procedure may be also recommended for the preservation of rumen samples.
\end{abstract}

Haihtuvien rasvahappojen määrittämisessä aikaisemmin käyțettyjä menetelmiä on hidastanut erityisesti näytteiden vaivalloinen esikäsittely. Työskenneltäessä kuumalankadetektorilla näytteiden vesiuutteen tislaus ja konsentroiminen sekä ekstrahointi orgaanisiin liuottimiin ovat olleet välttämättömiä analyysivaiheita (Gehrke \& Lamkin 1961, Fenner \& Elliot 1963). Liekkiionisaatiodetektorin käyttöönotto on nopeuttanut määritystä. Tällöin analysointi on voitu suorittaa suoraan vesiliuoksista, koska suuri vesiliuotinpiikki ei tule lainkaan näkyviin tässä detektorissa. Konsentroiminen on ollut tar- 
peetonta, koska detektori reagoi erittäin herkästi haihtuville hiiliyhdisteille. Probleemaksi on jäänyt lähinnä nopean, toistokykyisen ja kestävän patsaan löytäminen.

EMERy \& KOERner (1961) ja Erwin et al. (1961) analysoivat ensimmäisinä haihtuvia rasvahappoja kvantitatiivisesti liekki-ionisaatiodetektorilla. He käyttivät Tween-80-patsasta, josta rasvahapot valeriaanahappoon asti eluoituivat 19 min:ssa. Isovoihappo ja propionihappo erottuivat kuitenkin huonosti toisistaan. Patsaan kestävyydestä eivät tutkijat maininneet mitään. PAcketr \& McCUNE (1965) vertailivat viiden erilaisen patsaan ominaisuuksia rasvahappojen kvantitatiivisessa analyysissä ja totesivat fosforihapolla stabilisoidun Lac-296-polyesterin kestäväksi patsasmateriaaliksi. He kehittivät myös mikrobiologisten elatusainenäytteiden esikäsittelyyn ja säilytykseen sopivan rutiinimenetelmän. Rasvahapot säilyivät puoli vuotta vesiliuoksessa, jossa oli $25 \%$ rikkihappoa ja metafosforihappoa. Epätäydellisesti saostunut proteiini aiheutti kuitenkin perusviivavaikeuksia kromatografoinnin aikana ja piikit oli mitattava käsin integraattorin asemesta.

Koska Kotieläinhoidon tutkimuslaitoksessa on jouduttu analysoimaan tuhansia säilörehu- ja pötsinäytteitä, on nopean rutiinimenetelmän kehittäminen rasvahappojen määrittämiseksi näistä näytteistä ollut tarpeellista. Tässä tutkimuksessa on selvitelty kylmäkuivauksen soveltuvuutta pötsinesteiden esikäsittelytoimenpiteenä sekä rasvahappojen säilymistä kylmäkuivattuina $-18^{\circ} \mathrm{C}$ :ssa. Säilörehujen ja pötsinesteiden kromatografoinnissa kokeiltiin helposti valmistettavan ja nopeasti eluoivan patsaan kestävyyttä ja tarkkuutta.

\section{Materiaalit ja menetelmät}

Säilörehun ja pötsinesteen esikäsittely

Rasvahapot ekstrahoitiin veteen sekoittamalla 5 min:n ajan tehosekoittajassa (Braun) $32 \mathrm{~g}$ kosteata, lyhyeksi silputtua säilörehua ja $268 \mathrm{ml}$ ioninvaihtovettä. Seos jäähdytettiin $4^{\circ} \mathrm{C}$ :ssa ja sekoittamista jatkettiin vielä 5 min. Tämän jälkeen vesiuute suodatettiin imussa Whatman 1 suodatinpaperin läpi. Myös 20, 30, 40 ja 50 min:n pituisia ekstrahointeja kokeiltiin, jolloin jäähdytys suoritettiin 10 min:n välein. Kaasukromatografoimista varten lisättiin säilörehusuodokseen $5 \%$ muurahaishappoa (Merck p.a.) ja $0.5 \%$ ortofosforihappoa (Merck p.a.). Liuos sekoitettiin ja sentrifugoitiin.

Pötsinesteet sentrifugoitiin 10 min 2000 kier./min. Päällimmäisenä olevaa liuoskerrosta pipetoitiin $5 \mathrm{ml} 50 \mathrm{ml}: \mathrm{n}$ injektiopulloihin, joihin lisättiin $0.5 \mathrm{ml}$ kyllästettyä merkurikloridiliuosta mikrobitoiminnan tyrehdyttämiseksi sekä $2 \mathrm{ml} 1 \mathrm{~N}$ natriumhydroksidiliuosta rasvahappojen suoloiksi muuttamista varten. Näytteet kylmäkuivattiin Vacuum Stoppering Tray Dryer-merkkisessä kylmäkuivauslaitteessa 18 t. Näytepullot suljettiin kuivauksen jälkeen vakuumissa erikoistulpilla ja ne säilytettiin $-18^{\circ} \mathrm{C}$ :ssa. Pötsinäytteiden ohella kylmäkuivattiin samalla tavalla esikäsiteltyjä tunnettuja rasvahapposeoksia, joiden säilyvyyttä seurattiin vuoden ajan.

Kaasukromatografoimista varten lisättiin kylmäkuivattuun pötsinesteeseen 
$0.25 \mathrm{ml} 85 \%$ fosforihappoa. Sakka sekoitettiin fosforihappoon lasisauvalla ja liuotettiin $40 \mathrm{ml}$ :aan $5 \%$ muurahaishappoa. Liuos sekoitettiin huolellisesti ja annettiin seistä yli yön $4^{\circ} \mathrm{C}$ :ssa. Kirkkaan liuoksen annettiin lämmetä $10^{\circ} \mathrm{C}$ :een ennen ruiskutusta. Standardiliuoksina käytettiin erivahvuisia, puhtaista, kaupallisista rasvahapoista (Fluka) valmistettuja seoksia. Nämä liuokset sisälsivät, kuten näyteliuoksetkin $5 \%$ muurahaishappoa ja $0.5 \%$ fosforihappoa. Joka kuukausi valmistettiin uudet standardiliuokset.

\section{Laitteisto}

Rasvahappojen kromatografoiminen suoritettiin laitteistolla, johon kuului vetyliekki-ionisaatiodetektorilla varustettu Perkin Elmer F 11 kaasukromatografi, Hitachi piirturi, Perkin Elmer D 26 elektroninen integraattori ja Kienzles laskijalaite. Detektori oli kytketty välittömästi integraattoriin herkkyydellä 1: 1 ja piirturiin herkkyydellä 32: 1. Kolonna oli spirallimainen lasikolonna, jonka pituus oli $200 \mathrm{~cm}$ ja sisäinen halkaisija $3 \mathrm{~mm}$. Kolonnamateriaalin kiinteänä faasina käytettiin hapolla pestyä Chromosorb W:tä (60/80 messin fraktio, John Manville-tehtaan tuote) ja nestefaasina dietyleeniglykolisukkinaattia (Hi-Eff IB, Appl. Sci. Lab.) ja ortofosforihappoa (Merck p.a.). Kiinteätä faasia punnittiin $20 \mathrm{~g}$ haihdutuskolviin, jossa oli asetonia (Merck p.a.), lisättiin $1 \mathrm{~g}$ nestefaasia ja $0.25 \mathrm{~g} 85 \%$ fosforihappoa molemmat liuotettuina asetoniin. Sekoituksen jälkeen haihdutettiin asetoni pois kierrehaihduttimessa ja massaa kuivattiin vielä $110^{\circ} \mathrm{C}$ :ssa tunti. Kolonna pakattiin tiiviiksi imussa ja paistettiin typpikaasuvirrassa $(20 \mathrm{ml} / \mathrm{min}) 140^{\circ} \mathrm{C}: \mathrm{ssa}$ $16 \mathrm{t}$.

Kromatografoimisen aikana olivat lämpötilat uunissa $100^{\circ} \mathrm{C}$ ja injektiokohdassa $180^{\circ} \mathrm{C}$. Typpikantokaasun, vedyn ja ilman virtausnopeudet olivat 40,30 ja $200 \mathrm{ml} / \mathrm{min}$ vastaavasti.

\section{Ruiskutus.}

Ruiskutuksessa käytettiin $10 \mu \mathrm{l}$ :n Hamilton mikroruiskua. Kvantitatiivisesti ruiskutettaessa määritettiin ruiskussa ennen ruiskutusta ja senjälkeen oleva liuostilavuus vetämällä liuos kokonaan kalibroitavalle alueelle ja lukemalla tilavuus suurennuslasilla $0.02 \mu \mathrm{l}: \mathrm{n}$ tarkkuudella. Liuostilavuus, joka jäi ruiskuun ruiskutuksen jälkeen vähennettiin alkuperäisestä tilavuudesta. Todellinen ruiskutus pyrittiin säätämään noin $1 \mu \mathrm{l}$ :n tienoille. Ruisku puhdistettiin erilaisten näyte- ja standardiruiskutuksien välillä imussa ioninvaihtovedellä, metanolilla ja eetterillä sekä imettiin kuivaksi. Toisella ruiskulla ruiskutettiin $1 \mu \mathrm{l}$ vettä jokaisen näyteruiskutuksen jälkeen kolonnan ja detektorin puhdistamiseksi. Injektiokanavassa käytettiin lasikapillaaria, joka vaihdettiin päivittäin. Näytteistä ja standardeista tehtiin tavallisesti kaksi rinnakkaisruiskutusta, tarvittaessa kolme. Rinnakkaisarvojen ero sai olla korkeintaan $3 \%$. Näytteiden konsentratiota vastaavia standardiseosliuoksia kromatografoitiin päivittäin useampaan kertaan. 


\section{Tulokset ja tulosten tarkastelu}

Tutkimuksessa todettiin 10 min:n pituinen ekstrahoiminen yhtä tehokkaaksi kuin $20,30,40$ ja 50 min:n ekstrahoinnit. Kirjallisuudessa on esitetty hyvin erilaisia säilörehun ekstrahoimistapoja. DANIEL (1971) ekstrahoi säilörehua tunnin ajan $0.1 \mathrm{~N}$ rikkihapolla, mutta hän ei käyttänyt tehosekoittajaa. RUMSEY et al. (1967) ekstrahoivat tehosekoittajalla säilörehua 30 sek kaksi kertaa jäähdyttäen välillä. Näin lyhytaikainen ekstrahointi ei riittäne rasvahappojen uuttamiseen kuivahkoista säilörehuista.

Rasvahappojen erottuminen patsaassa kromatografoinnin aikana ilme-

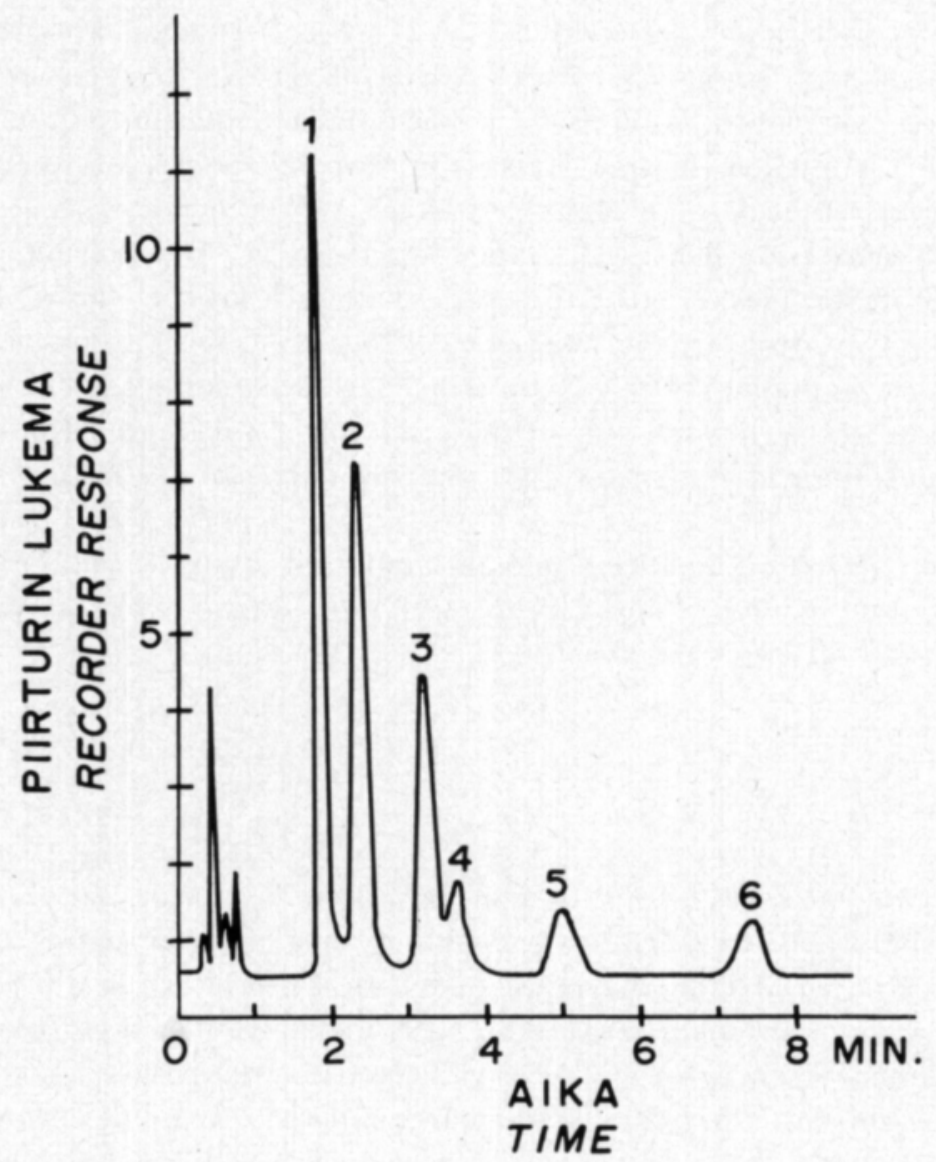

Kuva 1. Haihtuvien rasvahappojen kromatogrammi: 1. etikkahappo, 2. propionihappo, 3. voihappo, 4. isovaleriaanahappo, 5. valeriaanahappo ja 6. kapronihappo. Typpikantokaasun virtausnopeus $40 \mathrm{ml} / \mathrm{min}$, uuninlämpötila $100^{\circ} \mathrm{C}$, injektiolämpötila $180^{\circ} \mathrm{C}$. Näytteen määrä $1 \mu$ l. Piirturin herkkyys 1/32. Elektronisen integraattorin herkkyys 1.

Figure 1. Chromatogram of volatile fatty acids: 1. acetic acid, 2. propionic acid, 3. butyric acid, 4. isovaleric acid, 5. valeric acid and 6. capronic acid. Nitrogen carrier gas at $40 \mathrm{ml} / \mathrm{min}$, oven temperature $100^{\circ} \mathrm{C}$, injection temperature $180^{\circ} \mathrm{C}$ Sample volume 1 pl. Recorder sensitivity 1/32. Electronic integrator sensitivity 1. 
nee kuvasta 1. Etikkahapon, propionihapon, voihapon, isovaleriaanahapon, valeriaanahapon ja kapronihapon retentioajat olivat 1.85, 2.35, 3.20, 3.65, 5.00 ja $7.50 \mathrm{n}$ in vastaavasti. Isovoihappo tuli samanaikaisesti propionihapon kanssa. Pötsinesteissä oli hyvin vähän ja säilörehussa ei ollenkaan isovoihappoa, joten sitä ei otettu huomioon määrityksessä. Kapronihappoakaan ei huomioitu, koska se olisi pidentänyt ajoaikaa ja koska sitä ei esiintynyt pötsinesteissä lainkaan ja säilörehussakin hyvin harvoin.

Rasvahappopikit olivat teräviä ja adsorbiota ei esiintynyt. Polaariset rasvahapot adsorboituvat patsaan kiinteään faasiin ellei nestefaasia ja fosforihappoa ole käytetty riittävästi. Adsorboituneen hapon piikki on epäsymmetrinen ja ilmestyy uudelleen pienempänä vesiruiskutuksen aikana. Tässä tutkimuksessa käytetyssä patsaassa nestefaasin ja fosforihapon määrät olivat sopivia. Adsorbtiota esiintyi heti, kun nestefaasia käytettiin liian vähän. Nestefaasin lisäys taas pidensi huomattavasti retentioaikoja sekä levensi varsinkin isovaleriaanahapon ja valeriaanahapon piikkejä, joiden integroiminen tuli epätarkaksi. GIESECKE (1966) käytti enemmän (15\%) samanlaista nestefaasia kuin tässä tutkimuksessa $(5 \%)$ ja sai kapronihapon retentioajaksi $30 \mathrm{~min}$; isovoihappo ja propionihappo eivät kuitenkaan erottuneet toisistaan tarpeeksi. Adsorbtiota estivät myös injektiokanavassa käytetty kapillaari ja näyteliuoksiin lisätty muurahaishappo. Tämä happo ei tule näkyviin liekki-ionisaatiodetektoria käytettäessä.

Tässä tutkimuksessa käytetty patsas kesti n. 2000 rasvahapporuiskutusta, koska käytettiin alhaista lämpötilaa. Metcalfe (1963) ja Nikelly (1964) totesivat samanlaisen patsaan kestämättömäksi käyttäessään lähellä $180^{\circ} \mathrm{C}$ päättyvää lämpötilaohjelmointia. Pötsinesteiden rasvahappomäärityksissä ei ilmennyt minkäänlaisia perusviivavaikeuksia, mikä osoittaa kylmäkuivauksen hyvin soveltuneen pötsinesteiden esikäsittelytoimenpiteeksi. Detektori pysyi myös puoli vuotta puhtaana. Säilörehujen rasvahappoajoissa estettiin hiiliyhdisteiden kerääntyminen injektiokanavaan päivittäin vaihdettavalla injektiokapillaarilla.

Etikkahappo ja propionihappo, samoin kuin voihappo ja isovaleriaanahappo eivät aivan täydellisesti eronneet toisistaan (kuva 1). Piikit olivat kuitenkin täysin symmetrisiä, joten integraattori säädettiin laskemaan piikkien alat yhteenmeneviltä kohdilta kohtisuorasti pohjaviivaa vastaan. Automaattista pohjaviivan korjausta käytettiin myös hyväksi. Kaikki viisi rasvahappoa voitiin määrittää lineaarisesti. Kymmenen kertaa vahvemmassa konsentratiosuhteessa etikkahapon piikki suurensi hieman propionihapon piikkiä. Voihapon piikki ei vaikuttanut isovaleriaanahapon piikkiin.

Arvioitaessa rasvahappomäärityksen tarkkuutta laskettiin 50:sta eri pötsinäytteestä suoritetusta kahdesta rinnakkaisruiskutuksesta saadut rasvahappojen konsentratioiden suhteellisten virheprosenttien keskiarvot. Ne olivat seuraavat: etikkahappo $1.77 \%$, propionihappo $1.67 \%$, voihappo $2.55 \%$, isovaleriaanahappo $3.21^{-} \%$ ja valeriaanahappo $3.35 \%$. Isovaleriaanahapon ja valeriaanahapon määrityksessä suhteelliset virheet olivat suurimmat, johtuen siitä, että niiden konsentratio oli kahdeskymmenesosa etikkahapon konsentratiosta. Isovaleriaanahapon ja valeriaanahapon määritystarkkuus pieneni happojen konsentratioiden laskiessa alle 10 ppm:n. 
Tutkimuksessa todettiin, että tunnetut rasvahappoliuokset, jotka käsiteltiin samoin kuin pötsinesteetkin ennen kylmäkuivausta, säilyivät $-18^{\circ} \mathrm{C}$ :ssa muuttumattomina vuoden ajan.

\section{Yhteenveto}

Tässä tutkimuksessa käytetty kaasu-nestekromatograafinen haihtuvien rasvahappojen määritysmenetelmä oli luotettava 10 ppm:n konsentratioon. Säilörehun ja pötsinesteiden haihtuvat rasvahapot määritettiin vetyliekkiionisaatiodetektoria hyväksikäyttäen $\mathbf{5} \%$ muurahaishappoa sisältävästä vesiekstraktista. Lasisen spirallikolonnan (pit. $2 \mathrm{~m}$, sis. halk. $3 \mathrm{~mm}$ ) täytemateriaalina käytettiin dietyleeniglykolisukkinaatilla (5\%) ja ortofosforihapolla (1\%) päällystettyä kiinteätä faasia Chromosorb W (a.w. 60/80 mesh). Kolonnan täyte oli vaihdettava vasta 2000 analyysin jälkeen. Etikkahappo, propionihappo, voihappo, isovaleriaanahappo ja valeriaanahappo määritettiin 5 min:ssa. Vastaavat rinnakkaismääritysten suhteelliset virheprosentit olivat keskimäärin $1.17,1.67,2.55,3.21$ ja 3.35 . Suhteellinen virhe oli suurin isovaleriaanahapon ja valeriaanahapon määrityksessä, koska näitä happoja oli kahdeskymmenesosa etikkahapon määrästä.

Kyllästetyn merkurikloridin ja $1 \mathrm{~N}$ natriumhydroksidin lisääminen sentrifugoituihin pötsinesteisiin ja kylmäkuivaus osoittautuivat hyväksi esikäsittelyksi myös kaasukromatografoinnin kannalta, koska perusviiva pysyi stabiilina koko ajan. Puhtaat haihtuvien rasvahappojen liuokset, jotka esikäsiteltiin e.m. tavalla, säilyivät $-18^{\circ} \mathrm{C}$ :ssa muuttumattomina vuoden ajan, joten tällaista esikäsittelyä voinnee suositella myös pötsinesteiden säilytystä varten.

\section{KIRJALLISUUS}

DANIEL, P. 1971. Zur Methode der gas-chromatographischen Bestimmungen der Gärsäuren und der Vergleich mit der Destillationsmethode nach Lepper-Flieg. Das wirtschaftseig. Futter 17, 3:234-244.

EMERY, E. M. \& KoERner, W. E. 1961. Gas chromatographic determination of trace amounts of the lower fatty acids in water. Anal. Chem. 33: 146-147.

Erwin, E. S., Marco, G. J. \& Emery, E. M. 1961. Volatile fatty acid analyses of blood and rumen fluid by gas chromatography. J. Dairy Sci. 44: 1768-1770.

FEnNer, H. \& Elliot, J. M. 1963. Quantitative method for determining the steam volatile fatty acids in rumen fluid by gas chromatography. J. Animal. Sci. 22: 624-630.

GeHRKe, C. W. \& LAMKIN, W. M. 1961. Quantitative determination of steam volatile fatty acids by gas-liquid chromatography. Agric. Food. Chem. 9, 1: 85-88.

GIESECKE, von D. 1966. Gas-chromatographische Bestimmung flüchtiger Fettsäuren und ihre Produktion im Pansen. Z. f. Tierernähr. u. Futtermittelk. 22: 354-364.

Metcalfe, L. D. 1963. The gas chromatography of fatty acids and related long chain compounds on phosphoric acid treated columns. J. Gas. Chrom. 1: 7-11.

Nikelly, J. G. 1964. Gas chromatography of free fatty acids. Anal. Chem. 36, 12: 2244-2248.

PACKetr, L. V. \& McCune, R. W. 1965. Determination of steam volatile organic acids in fermentation by gas-liquid chromatography. Appl. Microbiol. 13, 1:22-27.

Rumsey, T. S., Noller, C. H., Rhykerd, C. L. \& Burns, J. C. 1967. Measurement of certain metabolic organic acids in forage, silage and ruminal fluid by gas-liquid chromatography. J. Dairy Sci. 50: 214-219. 